\title{
Performance measurement of supply chain flexibility using witness
}

\author{
Rituraj Chandrakar $^{\mathrm{a}^{*}}$, Anil Kumar ${ }^{\mathrm{b}}$, Rajesh Kumar $^{\mathrm{c}}$ and Robin Joy ${ }^{\mathrm{d}}$
}

\author{
${ }^{a}$ Working as Lecturer in the Department of Mechanical Engineering at CSIT, DURG, India \\ ${ }^{b}$ Working as Assistant Professor in the Department of Mechanical Engineering at BIT, DURG, India \\ ${ }^{c}$ Working as Associate Professor and Head of Department in Mechatronics Engineering at CSIT, DURG, India \\ ${ }^{d}$ Master in Technology in Industrial Engineering From NIT Trichy, India
}

\section{A R T I C L E I N F O}

\section{Article history:}

Received April 25, 2012

Received in Revised form

June, 16, 2012

Accepted 28 June 2012

Available online

July 82012

Keywords:

Supply chain flexibility

Responsiveness

No flexibility

Limited flexibility

Total flexibility

Simulation

Performance

\section{A B S T R A C T}

\begin{abstract}
In today's global scenario of intense competition and environmental uncertainty flexibility in supply chain has an important role to play for the existence of any supply chain business. A need to be responsive to the constantly changing market scenario and cater to the customer needs, a certain degree of flexibility is required, which requires the coordination of many plants to produce and deliver goods to customers located in different places, and suppliers, which provide each plant with the required components. This paper intends to measure the degree of flexibility required for a two stage supply chain and assessing both the supplier flexibility and the assembler flexibility. In this paper, nine configurations of the SC are considered resulting from the combination of the three degrees of supplier and manufacturer flexibility, i.e. no flexibility, limited flexibility and total flexibility, respectively. Simulation model representing the different flexibility configurations are evaluated and the performance of each configuration analyzed to determine the flexibility configuration suitable to a supply chain. In particular the performance analysis of lead time, work-in-process, service level and cost are measured to determine the suitable flexibility.
\end{abstract}

\section{Introduction}

Supply chain flexibility (SCF) has become an essential requirement in today's competitive market. According to the present scenario of unstable and fluctuating economy there is a corresponding change in the customer and market requirement, to be able to meet this corresponding change, one must be flexible enough to accommodate the given changes in an acceptable speed and cost. Flexibility is required to meet unpredictable requirements and enhance the competitiveness. The need for flexibility has gained the research interest in the present circumstances, and companies have recognized its importance and are looking forward to its implementation in various fields mainly operations systems, logistics process, supply network, organizational design and information systems. The decisions involving implementation of flexibility in supply chain can be modeled and its purpose

* Corresponding author. Tel: +918966000067

E-mail addresses: riturajchandrakar@csitdurg.in (R. Chandrakar) 
validated using simulation. Thus, the performance characteristics used for evaluating the flexibility of supply chain can be evaluated using simulation. Measurement provides the opportunity for feedback, which supports the prevention or correction of problems identified during the measurement process and leads to the achievement of the desired result. It is noted that flexibility comes with associated costs, which increases as the degree of flexibility increases. This study aims to find the required level of flexibility for a given supply chain based on the performance characteristics of the supply chain flexibility.

\section{Literature review}

The global competition has made the supply chain (SC) long and complex and supply chain flexibility has been increasingly become important. The supply chains, which are slow to respond to the changes in the market and the uncertainty are most vulnerable. As pointed out by Gunasekaran et al. (2004) being flexible means having the capability to provide products or services that meet the individual demand of customers. Chung et al. (2006) suggests that a single optimization goal, such as throughput maximization or profit maximization that was previously pursued by companies, is not enough today to meet the production performance demanded by customers. Performance such as ontime delivery and production cycle time are highly emphasized by the customer. In supply chains that experienced an imbalance between demand uncertainty

and supply chain flexibility, manufacturers and suppliers were put under high pressure to increase their flexibility (Bertrand, 2003).

Performance is defined as the potential for future successful implementation of actions in order to reach the objectives and targets. Measurement is complex, frustrating, difficult, challenging, important, abused and misused as noted by Sink (1991). Lebas (1995) pointed out that performance per se may not be definable in the absolute but is contextual both in terms of users and in terms of purpose. Performance is about deploying and managing well the components of the casual model that leads to the timely attainment of stated objectives within constraints specific to the firm and to the situation. Performance is therefore case specific and decision-maker specific. The measurement of the performance characteristics for flexibility helps us to identify which factor might have a significant role on the flexibility configuration.

Lummus et al. (2003) identified SCF as important for several reasons. First, recent trends, such as mass customization, require SC to meet individual customer requirements without adding significant costs. Second, certain industries, particularly high-tech industries, require upside and downside flexibility, which is the ability to rapidly increase or decrease production (by $20 \%$ or more) to a new unplanned level and then sustain that level. Many innovative product categories, such as fashion apparels and electronic devices, uncertainty of demand is a fact of life and creating a responsive SC is one method of avoiding uncertainty (Fisher, 1997). Golden and Powell (2000) define flexibility as the capacity to adapt across four dimensions; temporal, range, intention, and focus. These dimensions define areas within which flexibility can be achieved. The extent of flexibility can be measured by its metric; efficiency, responsiveness, versatility and robustness.

Garavelli (2003) in his study shows that a way to optimize the product flows in SC is to adopt the concept of limited flexibility against total flexibility. Tang and Tomlin (2008) recommended using SCF to provide supply flexibility through several suppliers, provide flexible supply via flexible contracts, include a flexible process strategy via flexible contracts, including a flexible product strategy via postponement and present a flexible pricing strategy to avert SC disruption risks. Minner (2003) studied supply flexibility, reviewing the literature for inventory models that considered multiple supply options to reduce shortage, which allowed them to gain operational flexibility in global sourcing. The author favored multiple sourcing as a way to avert the risk associated with dependency on a single or small number of suppliers. The concept of agility has been extended to supply chain agility (Prater et al., 2001) with its component defined as speed and flexibility. 
Flexibility is further broken into the capabilities of promptness and the degree to which a firm adjust to its supply chain speed, destination and volumes. Gunasekran et al. (2001) stated that in SC where material moves sequentially from one trading partner to the next, firms have recognized that to be responsive to end customer demand, all partners in the chain must be flexible in responding to the change. This notion is reinforced in SC measurement literature as flexibility to meet particular customer needs, and is viewed as an important strategic performance metric. Escudero et al. (1999) propose a modeling framework for a supply chain with uncertainty in product demand, component supply cost, and delivery time. Gerwin (1993), for instance, suggests that the level of performance is contingent on a firm's ability to achieve a fit between the environmental uncertainty it faces and the degree of manufacturing flexibility it establishes. The basic reasoning is that flexibility is important for quickly reacting to changes in the environment, but that flexibility is also expensive and that the benefits of flexibility must be traded off against the cost of flexibility. A match of uncertainty and flexibility results in high performance, a mismatch results in low performance. Supply chain flexibility, embraces a process-based view and also includes the core processes procurement/sourcing and distribution/logistics. Thus, it is a much broader concept, considering flexibility from the perspective of the entire value chain (Vickery et al., 1999).

Chang et al. (2006) conducted an empirical study involving 105 manufacturing firms, and concluded that supplier involvement enhanced manufacturing flexibility in ways that ultimately contributed to higher business performance. Avittathur and Swamidass (2007) show in an empirical study of 26 manufacturing plants and their small suppliers in India that flexibility or inflexibility of both partners in a supply chain results in higher performance than a flexible-inflexible combination. Vickery et al. (1999) analyze the direct relationship between uncertainty and supply chain flexibility in the US furniture industry and do not find a significant relationship between the two constructs. Sanchez and Perez (2005) examine 126 Spanish automotive suppliers and find a significant direct relationship between environmental uncertainty and supply chain flexibility. Swafford et al. (2008) conducted an empirical study to determine the effect of IT integration on the SC process-specifically in regards to SC flexibility and SC agility. Based on their data analysis, they concluded that IT integration improved SC flexibility and SC agility. The paper also concluded that SC flexibility and agility were two distinct concepts, in which higher levels of flexibility could provide higher levels of agility. Chan and Chan (2010) proposed a two-echelon SC inventory cost model to study the influence that flexibility and adaptability had on delivery quantity and due date in a make-to-order (MTO) SC. The study concluded-based on a simulation run-that both flexibility (flexible capacity for MTO) and adaptability would provide better cost than order-up-to policy model costs. Based on the research mentioned above, it is evident that creating flexibility within an SC potentially addresses uncertainty in addition to improving other business performances. Since most SC risks are rooted in uncertainty, flexibility creation would also contribute to the mitigation of such risks.

Simulation models are increasingly being used to analyze complex supply chain problems (Reiner 2005; Holweg et al. 2005). To satisfy customer demands for shorter lead times, increased delivery frequency, and improved product and process quality, a simulation model was adopted by Jansen et al. (2001) to study a catering supply chain in the Netherlands. In their study, various distribution scenarios were tested for logistical and financial performances. Jain et al. (1999) used simulation to understand the behavior of supply chain networks and were able to identify the major issues surrounding such networks. Towill et al. (1992) compared different quick-response-to-orders strategies based on a supply chain simulation model. They concluded that collaboration between all players within the supply chain could result in great benefits. Jain et al. (2001) also proposed a framework for supply chain analyses. Critical elements in the framework included product characteristics, demand volumes and profiles, distribution centre lead times, supplier lead times, cost data, strategic options, supply chain structure scenarios, and performance indicators (e.g., service levels, lead times, and inventory turnover). Reiner (2005) also establishes a discrete-event simulation model to evaluate supply chain process improvements. Other people studied the effect of bullwhip 
effect on using simulation and he points out that simulations can measure different performances: reactions of participants to sudden changes in customer demands (the bullwhip effect), changes in supply level in a time, surplus of inventory goods, costs of SC participants and of the entire SC.

Tiger and Simpson (2003) describe the methodology for the use of discrete event simulation to evaluate the importance of time and flexibility in various SC. They highlight that the inadequacy of solving or optimizing of many systems can be achieved through simulation regardless of their complexity. The paper provides solutions for the flexible SC problems of timing and selection. They also advocate the use of outsourcing to the experts in order to find solutions to the complex problems in the SC network. Garavelli (2003) use simulation to optimize the product flow in supply chains, and evaluated different flexibility configurations. He concludes that a certain degree of flexibility against a total flexible system is required to respond to uncertainty and be competitive.

\section{Performance measurement of supply chain flexibility using witness}

\subsection{Problem description}

To determine the performance of the different flexibility configuration on both the supplier as well as the manufacture side and determine which configuration is preferable. Three flexibility configurations i.e. no flexibility configuration, limited flexibility configuration, and total flexibility configuration are measured both on the supplier and the manufacturer side and also a combination of above three configurations are also measured.

\subsection{Proposed procedure}

The flexibility configurations are defined for the performance evaluation of the supplier and manufacturer side supply chain flexibility conditions. There are a total of nine flexibility configurations defined which is characterized by five suppliers, five manufacturing units, five products and five markets. The configurations were selected according to the flexibility configurations defined by (Garavelli, 2003).

The simulation of the model is carried out in WITNESS simulation package. It allows representing real world processes in a dynamic animated computer model and then experimenting with "what-if" alternative scenarios to identify the optimal solution. The generalized steps for representing the model can be summarized as given below in Fig 1.

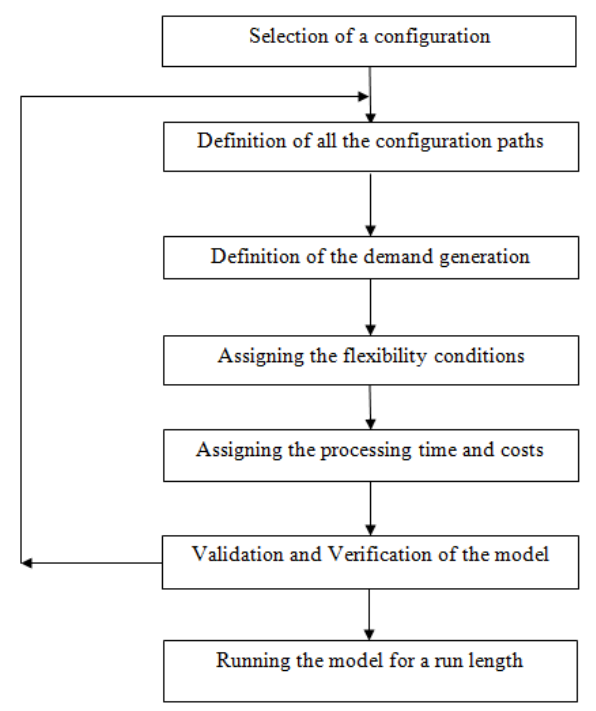

Fig. 1. Steps involved for modeling a configuration 
In this study, nine configurations of the $\mathrm{SC}$ are considered resulting from the combination of the three degrees of supplier and manufacturer flexibility, i.e. no flexibility, limited flexibility and total flexibility, respectively. The no flexibility condition or a focused supplier means that a supplier is able to deliver only one type of component. In case of total flexibility or flexible supplier a supplier is able to deliver all the components to a manufacturer. The limited flexibility configuration for e.g. if the supplier flexibility is two then a supplier supplies two components to a manufacturer. The maximum limited flexibility in this study would be limited to four. As far as manufacturer flexibility is concerned for no flexibility configuration every plant produces just one product and this focused plant then provides every market with its own product. The total flexibility of a manufacturer means that each plant produces every product for its own local market. The limited flexibility for a manufacturer for e.g. if the flexibility is three then every plant manufactures three products and delivers it to all the markets.

\begin{tabular}{|c|c|c|c|}
\hline \multirow{4}{*}{ No } & Configuration 1 & Configuration 2 & Configuration 3 \\
\hline & $\begin{array}{l}\text { Focused manufacturer and } \\
\text { global delivery }\end{array}$ & $\begin{array}{l}\text { L.F. manufacturer and } \\
\text { global delivery }\end{array}$ & $\begin{array}{l}\text { Flexible manufacturer and } \\
\text { local delivery }\end{array}$ \\
\hline & $\begin{array}{l}\text { Focused supplier and local } \\
\text { supply }\end{array}$ & $\begin{array}{l}\text { Focused supplier and } \\
\text { limited supply }\end{array}$ & $\begin{array}{l}\text { Focused manufacturer and } \\
\text { global supply }\end{array}$ \\
\hline & Configuration 4 & Configuration 5 & Configuration 6 \\
\hline 惡: & $\begin{array}{l}\text { Focused manufacturer and } \\
\text { global delivery }\end{array}$ & $\begin{array}{l}\text { L.F. manufacturer and } \\
\text { global delivery }\end{array}$ & $\begin{array}{l}\text { Flexible manufacturer and } \\
\text { local delivery }\end{array}$ \\
\hline Limited & L.F. supplier and limited supply & $\begin{array}{l}\text { L.F. supplier and limited } \\
\text { supply }\end{array}$ & $\begin{array}{l}\text { L.F. supplier and global } \\
\text { supply }\end{array}$ \\
\hline & $\underline{\text { Configuration } 7}$ & Configuration 8 & Configuration 9 \\
\hline & $\begin{array}{l}\text { Focused manufacturer and } \\
\text { global delivery }\end{array}$ & $\begin{array}{l}\text { L.F. manufacturer and } \\
\text { global delivery }\end{array}$ & $\begin{array}{l}\text { Flexible manufacturer and } \\
\text { local delivery }\end{array}$ \\
\hline & $\begin{array}{l}\text { Flexible supplier and global } \\
\text { supply }\end{array}$ & $\begin{array}{l}\text { Flexible supplier and } \\
\text { global supply }\end{array}$ & $\begin{array}{l}\text { Flexible supplier and local } \\
\text { supply }\end{array}$ \\
\hline
\end{tabular}

\section{Illustrative example}

Fig. 2. Characteristics of nine configurations

The market demand is modeled as stochastic variables exponentially distributed, with the same mean $\lambda$ and equal for all the markets. Each market demands the products produced by the company. The production process is modeled as a queue and First-in-first-out (FIFO) rule. The processing time is modeled as exponentially distributed stochastic variables, equal or every plant of a given configuration. Three flexibility conditions are considered, no flexibility, limited flexibility and total flexibility and each condition given a different processing time. The product distribution process from both the supplier and the manufacturer side is modeled as exponentially distributed stochastic variables, characterized by shorter mean and longer mean for distant transport. The cost for each of the local transport and the distant transport are taken to be equal with the local transport costing less compared to distant transport.

The simulation of nine flexibility configurations are carried out with the following parameters

- $\quad$ Demand of $\lambda=1 / 3=0.3333$

- Processing time in days: $\mu_{\mathrm{m}}=\mu_{\mathrm{s}}=1 / 0.65$ for no flexibility

$$
\begin{aligned}
& \mu_{\mathrm{m}}=\mu_{\mathrm{s}}=1 / 0.715 \text { for limited flexibility } \\
& \mu_{\mathrm{m}}=\mu_{\mathrm{s}}=1 / 0.65 \text { for total flexibility }
\end{aligned}
$$


- Distant transport times: $\mathrm{TT}_{\mathrm{d}}=2 \mu_{\mathrm{m}}=2 \mu_{\mathrm{s}}$;

- Local transport times: $\mathrm{TT}_{1}=1 / 2 \mu_{\mathrm{m}}=1 / 2 \mu_{\mathrm{s}}$

- Supplier processing cost

o $\quad$ Fixed cost $=$ Rs.50per day

o Cost per operation $=$ Rs. 60 per day

o Idle cost $=$ Rs. 5 per day

- Manufacturer processing cost

$0 \quad$ Fixed cost $=$ Rs.200per day

0 Cost per operation $=$ Rs. 60 per day

o Idle cost $=$ Rs. 1000 per day

- Supplier side inventory cost

0 Fixed cost $=10$ per day

o Cost per unit time $=20$ per day

- Manufacturer side inventory cost

$0 \quad$ Fixed cost $=5$ per day

0 Cost per unit time $=5$ per day

- Local transport cost

o $\quad$ Fixed cost $=$ Rs. 1000 per travel

o Cost per operation $=$ Rs. 2500 per day

o Idle cost $=$ Rs. 1000 per day

o Cost per operation $=$ Rs. 500

- Distant transport cost

o Cost per operation $=$ Rs. 5000 per day

o $\quad$ Cost per operation $=$ Rs. 10000

The no flexibility configuration with focused manufacturer and global delivery along with focused supplier and local supply represented by configuration 1 is modeled with all the products supplied to all the markets. This configuration has a local transport on the supplier side and local and distant delivery on the manufacturer side. Configuration 2 consists of limited manufacturer flexibility having a global supply to all the markets. Three flexibility options exist on the manufacturer side with flexibility $F=2,3,4$, these flexibility options are modeled with focused supplier and limited flexibility of the supplier. Configuration 3 has total flexibility from the assembler side and no flexibility on the supplier's side. Manufacturer delivers all the five products to the local market and supplier is a focused one with global supply.

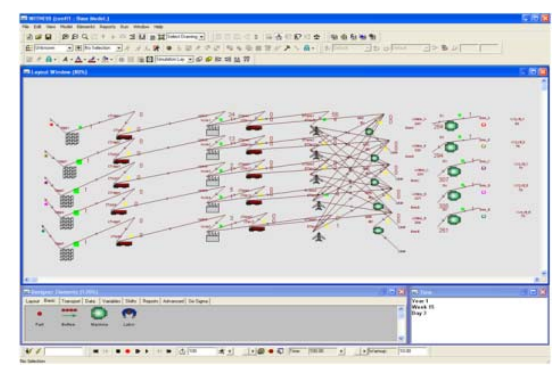

Screenshot of simulated model for configuration 1

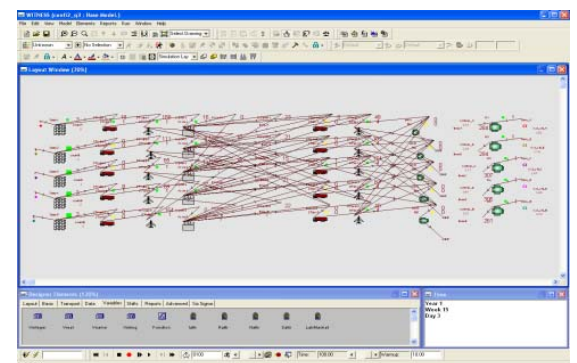

Screenshot of simulated model for configuration 2 with $F=3$

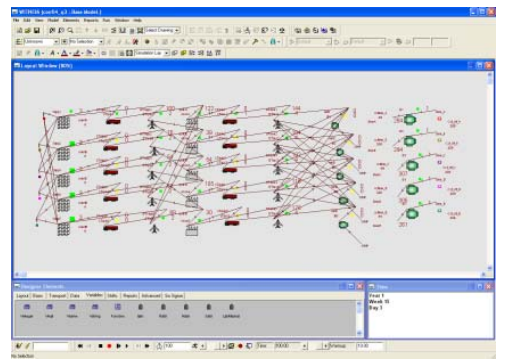

Screenshot of simulated model for configuration 4 with $F=3$

Configuration 4 is characterised by limited flexibility supplier and no flexibility of the manufacturer. The supplier supplies limited number of components and the manufacturer delivers the product globally to all the markets. Configuration 5 has the limited flexibility condition for both the supplier and the manufacturer. The five products are delivered to all the local markets by each manufacturer. Configuration6 has the limited flexibility supplier and global delivery whereas the manufacturer is totally flexible and delivers the product produced by it to the local market. Configuration 7 is 
characterised by total flexible supplier and no flexibility manufacturer, whereas configuration 8 is modelled for limited flexibility manufacturer and flexible supplier, both the configurations having global supply and global delivery. Configuration 9 has the total flexibility of both the supplier as well as the manufacturer and the delivery and supply is local to the market and manufacturer respectively.

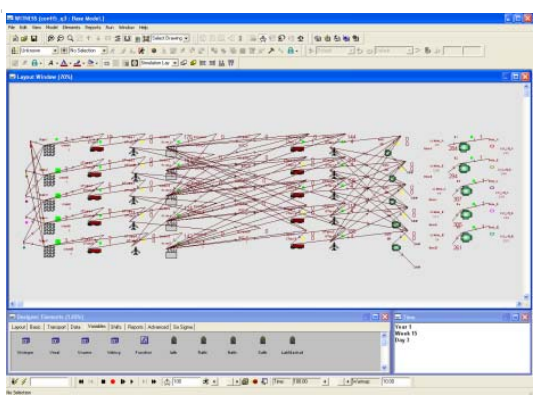

Screenshot of simulated model for configuration 5 with $\mathrm{F}=3$

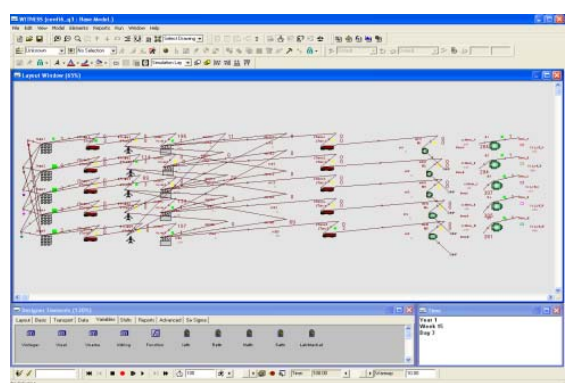

Screenshot of simulated model for configuration 6 with $\mathrm{F}=3$

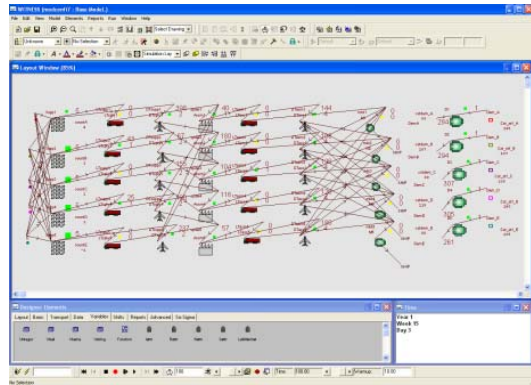

Screenshot of simulated model for configuration 7

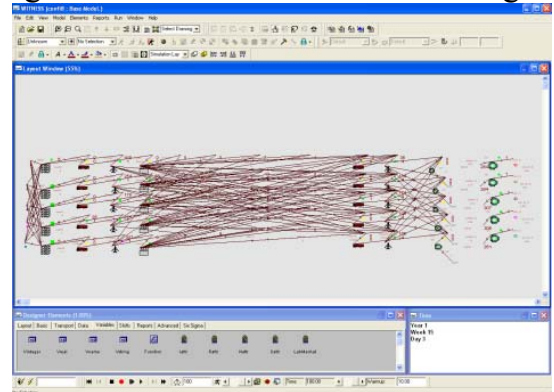

Screenshot of simulated model for configuration 8

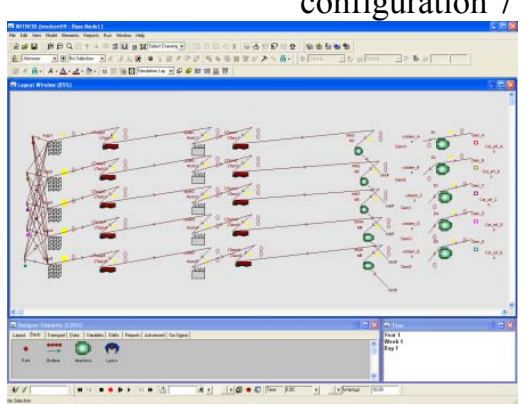

Screenshot of simulated model for configuration 9

The performance measures analysed in this study are the lead time, work in process, service level and the cost involved. The service level is obtained by demand generation and the measurement of the customers satisfied for the product. The lead time evaluated by the help of variables which give us the total processing time and the total time spent by product in inventory or in queue. The cost and the work in process are evaluated with the simulation tool itself directly.

\section{Results and conclusion}

The simulation was carried out for the nine different flexibility conditions and the results obtained is represented in Table 1.

\section{Table 1}

Performance measures for different flexibility configurations

\begin{tabular}{lllll}
\hline Configuration & WIP & Lead Time (days) & Service Level & Cost (Rs.) \\
\hline 1 & 25 & 5.71 & 0.38 & $30,16,827$ \\
2(Flexibility=2) & 180 & 6.43 & 0.61 & $88,41,968$ \\
2(Flexibility=3) & 259 & 7.32 & 0.58 & $1,09,39,322$ \\
2(Flexibility=4) & 332 & 8.46 & 0.54 & $96,20,754$ \\
3 & 420 & 2.61 & 1 & $83,94,173$ \\
4(Flexibility=2) & 227 & 6.13 & 0.67 & $1,1086,243$ \\
4(Flexibility=3) & 302 & 7.37 & 0.75 & $1,12,97,098$ \\
4(Flexibility=4) & 375 & 8 & 0.68 & $1,57,00,399$ \\
5(Flexibility=2) & 230 & 6.11 & 0.74 & $91,68,485$ \\
5(Flexibility=3) & 303 & 6.6 & 0.68 & $79,26,279$ \\
5(Flexibility=4) & 377 & 5.9 & 0.68 & $1,03,35,146$ \\
6(Flexibility=2) & 57 & 3.07 & 0.62 & $49,61,450$ \\
6(Flexibility=3) & 172 & 1.82 & 1 & $43,52,230$ \\
6(Flexibility=4) & 237 & 1.27 & 1 & $48,38,176$ \\
7 & 471 & 8.09 & 0.68 & $1,13,37,651$ \\
8 & 461 & 8.41 & 0.63 & $1,11,11,108$ \\
9 & 103 & 0.71 & 1 & $36,54,595$ \\
\hline
\end{tabular}


The comparison of the different configurations can be evaluated for the performance measures noted for a particular configuration with the help of fig. 3. It is interesting to note that as we go from configuration 1 to 3 the manufacturer flexibility increases and no supplier flexibility there is no significant improvement in the WIP and the cost associated, as the WIP as well as the cost goes on increasing. However, the service level and the lead time performance gets improved with the increase in the manufacturer flexibility. The configuration 1, 4, 7 with supplier flexibility increasing and no manufacturer flexibility there is no improvement in the WIP, lead time and the cost involved. However, the service level increases which is not so significant. The configuration of limited flexibility for both the supplier and the manufacturer shows configuration shows a good performance as there is a significant increase in the service level and the reduction of lead time, but the WIP increases.

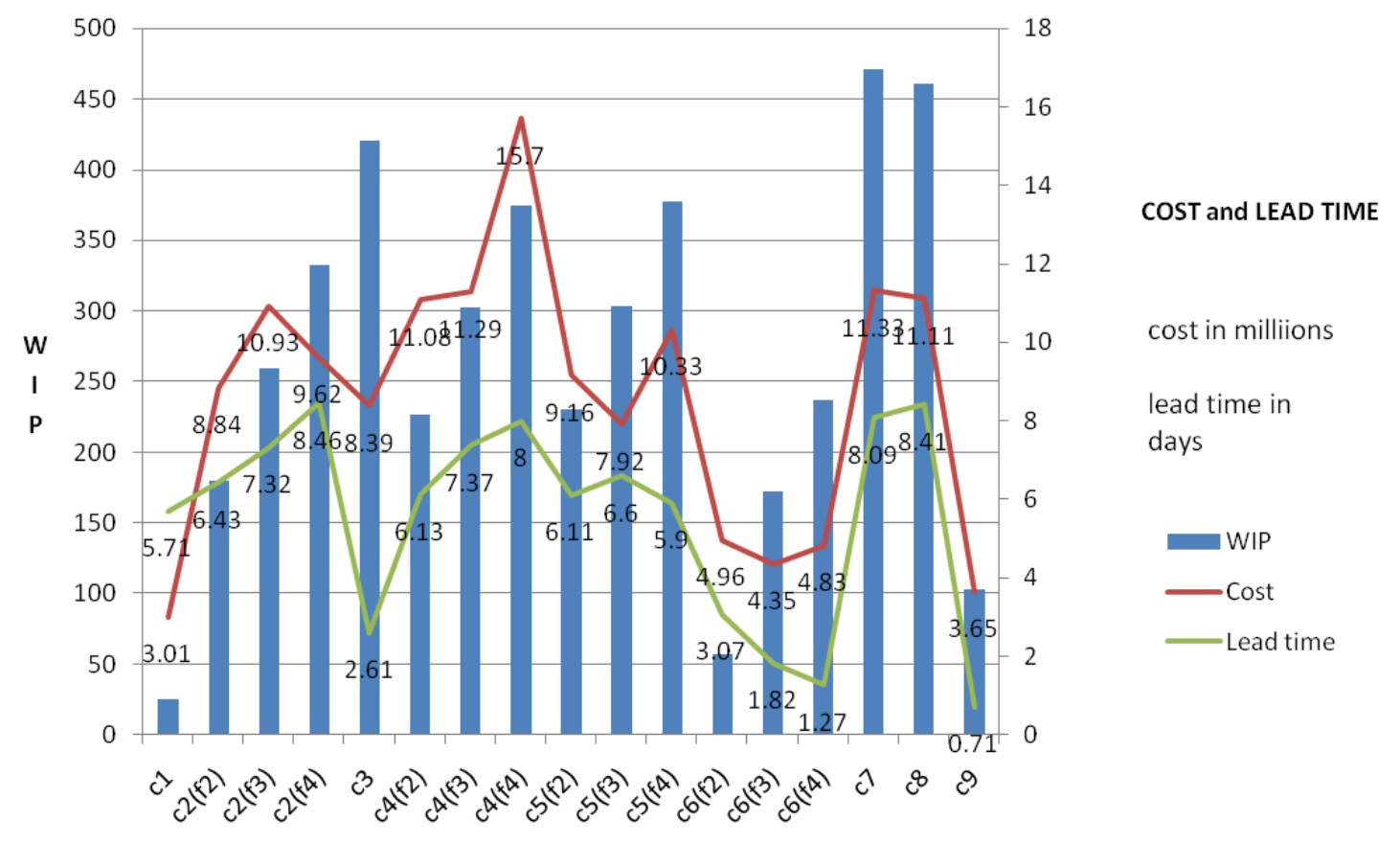

Fig. 3. Comparison of WIP, Lead time and Cost performance measures

The limited flexibility condition particularly configuration 6 improves the overall performance of the system. The configurations 3, 6, 9 shows the optimum service level and stresses the need for the assembler flexibility, but assembler flexibility alone does not give the desired results.

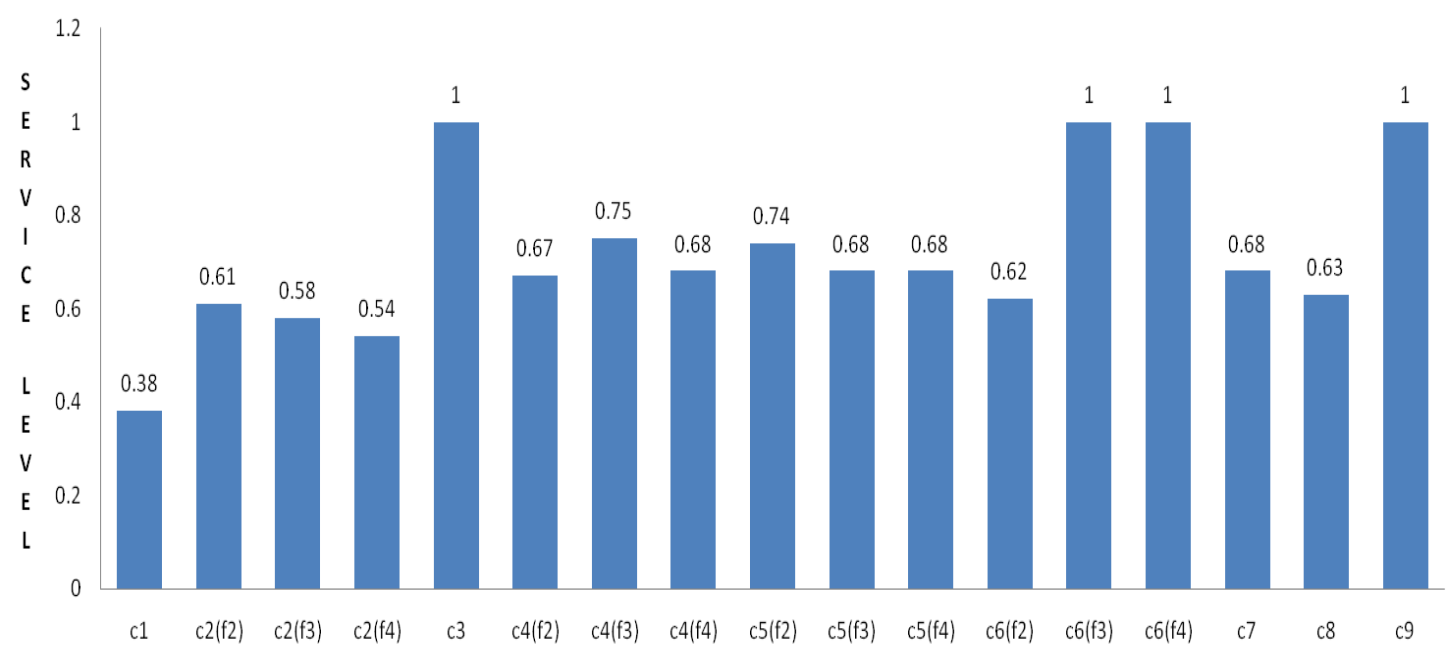

Fig. 4. Service level performance of different configurations 
The limited flexibility of both the supplier and manufacturer gives us a better performance. The higher levels of WIP and greater lead time for the configuration 5, 7, 8 can be attributed to distortion of the demand information i.e. Bullwhip effect. Configuration 6 with flexibility of three and four is showing the best performance with the minimum lead time, WIP, cost and maximum service level. Configuration 9 also shows good performance but is suited for SC, which can have a local manufacturer as well as a local supplier to impart the flexibility for each of the local market.

\section{Conclusion}

A simulation model characterized by five markets, plants and suppliers has been provided. Two extreme degrees of flexibility, namely total and no flexibility with an intermediate degree of flexibility, limited flexibility, have been defined. The three flexibility conditions define nine possible configurations. The results have shown that a combination of flexibility conditions from both the supplier side and manufacturer side can yield good results. The analysis pointed out that the manufacturer flexibility or supplier flexibility alone would lead to a better SC configuration and that the coordinated efforts of both would help to satisfy the uncertainty and changing customer demands. Simulation can help in understanding and developing the real case scenario of a SC network and the design and modeling of different configurations can help to achieve the desired optimum results. The best configuration has total flexibility manufacturer and limited flexibility of supplier.

\section{References}

Avittathur, B., \& Swamidass, P.M. (2007). Matching plant flexibility and supplier flexibility: lessons from small suppliers of US manufacturing plants in India. Journal of Operations Management 25 (3), $717-735$.

Barad,M., \& Sapir,D.E. (2005). Flexibility in logistics systems-modelling and performance evaluation. International Journal of Production Economics, 85, 155-170.

Chan, H.K., \& Chan, F.T.S. (2010). Comparative study of adaptability and flexibility in distributed manufacturing supply chains. Decision Support Systems 48, 331-341.

Chang, S.-C.,Chen, R.-H., Lin, R.J., Tien, S.-W., \& Shew, C. (2006). Supplier involvement and manufacturing flexibility. Techovation, 26, 1136-1146.

Chuu, S.J.(2011), Integrating group decision-making using a fuzzy linguistic approach for evaluating the flexibility in a supply chain, European Journal of Operational Research, 213, 279-289.

Das, K. (2011). Integrating effective flexibility measures into a strategic supply chain planning model, European Journal of Operation Research, 211, 170-183.

Escudero, L.F., Galindo, E., García, G., Gómez, E., \& Sabau,V. (1999), A modelling framework for supply chain management under uncertainty. European Journal of Operational Research, 119(1),1434.

Fisher, M.L. (1997). What Is the Right Supply Chain for your product?, Harvard Business Review, 75 (1), 91-101.

Garavelli, A.C. (2003). Flexibility configurations for the supply chain management. International Journal Production Economics, 85, 141-153.

Gerwin, D., (1993). Manufacturing flexibility: a strategic perspective. Management Science 39 (4), 395410.

Golden,W., \& Powell, P.(2000). Towards a definition of flexibility: in search of the holy grail?. Omega, 28, 373-384.

Gong, Z. (2008). An economic evaluation model of supple chain flexibility, European Journal of Operational Research, 184 745-758. 
Gunasekaran, A., Patel, C., \& Tirtiroglu, E. (2001) Performance measures and metrics in a supply Chain environment, International Journal of Operations Management, 21 (1/2), 71-87

Gunasekran, A., Patel, C., \& McGaughey, R.E. (2004) A framework for supply performance measurement, International Journal of Production Economics, 87, 333-347.

Holweg, M., Disney S. M., Hines P., \& Naim. M. M. (2005). Towards responsive vehicle supply: a simulation-based investigation into automotive scheduling systems. Journal of Operations Management, 23, 507-530.

Holweg, M., Disney S. M., Hines P., \& Naim. M. M. (2005). Towards responsive vehicle supply: a simulation-based investigation into automotive scheduling systems, Journal of Operations Management, 23, 507-530.

Jansen, D. R., Weert, A., Beulens, A. J. M., \& Huirne, R. B. M. (2001). Simulation model of multicompartment distribution in the catering supply chain, European Journal of Operational Research, 133, 210-224.

Jain, S, Collins, L.M, Workman, R.W, \& Ervin, E.C. (2001). Development of a high-level supply chain simulation model. Proceedings of the 2001 Winter Simulation Conference, 1129-1137.

Prater E., Beihl M. And Smith M.A, (2001). International supply chain agility; Tradeoffs between flexibility and uncertainty. International Journal of Operations Management, 21 (5/6), 823-839

Pujwan, N. (2004). Assessing supply chain flexibility: conceptual framework and case study. International Journal of Integrated Supply Management, 1, 79-94

Lummus, R.R., Duclos, L.K., \& Vokurka, R.J. (2003). Supply chain flexibility: Building a new model. Global journal of Flexible Systems Management, 4(4) 1-13.

Reiner, G. (2005). Customer-oriented improvement and evaluation of supply chain processes supported by simulation models. International Journal of Production Economics, 96, 381-395.

Sanchez, A.M., Perez, M.P. (2005). Supply chain flexibility and firm performance: A conceptual model and empirical study in the automotive industry. International Journal of Operations \& Production Management, 25(7), 681-700.

Sink, D.S. (1991). The role of measurement in achieving world class quality and productivity management. Industrial Engineering, 23(6), 23-28.

Swafford, P.M., Ghosh, S., \& Murthy, N. (2008). Achieving supply chain agility through IT integration and flexibility. International Journal of Production Economics 116, 288-297.

Tang, C., \& Tomlin, B.(2008). The power of flexibility for mitigating supply chain risks. International Journal of Production Economics, 116, 12-27.

Towill, D. R., Naim, M. M., \& Wikner, J. (1992). Industrial Dynamics Simulation Models in the Design of Supply Chains. International Journal of Physical Distribution and Logistics Management, 22(5), 313.

Vickery, S.K., Calantone, R., \& Droge, C. (1999). Supply chain flexibility: An empirical study. The Journal of Supply Chain Management: A Global Review of Purchasing and Supply, 35(3), 16-24. 